\title{
The Television Industry as a Market of Attention'
}

\author{
Tore Nilssen
}

\begin{abstract}
In this article, I present an economist's perspective on the TV industry and view it as a so-called two-sided market, with advertisers on the one side benefiting from the presence of TV viewers and TV viewers on the other side having a dislike for advertising on TV. I use this framework to discuss the likely future development of pay TV, in particular how a future increase in competition in the TV industry will affect the prevalence of pay TV over advertising-financed TV.
\end{abstract}

Keywords: TV industry, media financing, TV advertising, pay TV, DTTV, public broadcasting

\section{Introduction}

TV stations share a crucial feature with most other media firms - they serve two distinct groups of clients: on the one hand content consumers (i.e., TV viewers) who demand information and/or entertainment, and on the other hand advertisers who seek the attention of potential customers. The two groups affect each other's well being, in that TV viewers dislike advertising, whereas advertisers like viewers' attention. ${ }^{2}$

This means that, in the TV industry, we have a case of two-way externalities. In economics, markets with such a feature are called two-sided markets. ${ }^{3}$ A prominent example outside the media industries is the credit-card industry, with merchants and card users being the two groups in question. Sometimes, the firms in a two-sided market are called platforms, to catch the role they play between the two user groups. Thus, the phrase platform competition is another name for what goes on in a two-sided market.

A difference between the TV industry and many other two-sided markets is that the externalities in this particular industry go in opposite directions. While the two groups in the credit-card industry both benefit from the presence of the other group (merchants' benefits from joining a credit card company increase with the number of card users involved, and card users' benefits increase with the number of merchants available), viewers would prefer fewer rather than more advertisers on TV.

Another special feature in many TV markets in Europe is that there is a fairly limited number of TV firms operating, or, at least, the big majority of viewers are concentrated on a rather limited number of TV channels. ${ }^{4}$ Thus, we have a combination of imperfect competition and two-way externalities. The question to ask, then, is: how does a market with those two features work? 


\section{Digitization and Pay TV}

It is not possible to cover all aspects of this question in a short article. I will therefore focus on providing some comments on the role of pay TV. Pay TV means that TV firms give viewers access to their program content only if payment is received. This, of course, brings up questions on how to exclude non-payers from receiving TV signals. Until recently, the pay-TV segment was basically limited to cable TV, with cables bringing restricted TV signals out to paying households. However, recent technological advances have opened up for new ways of running pay TV. First, it is now possible to obtain payment from consumers without stretching cables, through satellites and digital terrestrial TV. ${ }^{5}$ Secondly, the TV industry can - and some TV firms already do - interact with the internet industry to obtain ways of getting viewer payment. ${ }^{6}$

Below, I explore some of the consequences of this development. On the one hand, we may expect to see TV firms introducing pay-TV operations where before there was only advertising-financed TV. So, what can we expect from the increased prevalence of pay TV in terms of program content? On the other hand, digital terrestrial TV in particular means that a greater number of TV channels are brought out to viewers through overthe-air transmission. This implies a potential increase in competition in the TV industry, and so the question is what effects we can expect from this increased competition when it comes to the role of pay TV.

\section{Pay TV and Program Content}

Consider first the effect of pay TV on program content. How competition affects the characteristics of products offered in the marketplace has been an issue in economics since the work of Hotelling (1929). The starting point for the discussion is that consumers - in our case, TV viewers - differ in terms of their preferences for these product characteristics. To be specific, think about possible TV programs as being somewhere between sports and movies, as in Figure 1, with "sports" indicating a program schedule containing sport events only and "movies" indicating one with movies only. Of course, this is an abstraction from reality, since TV programs vary in many dimensions. ${ }^{7}$ But as with many models in economics, it is a useful abstraction. Viewers come in many shapes, and we can think of them as being distributed along the line in Figure 1 according to what their ideal program mixes are: Viewers to the very left prefer a sports-only TV channel, viewers to the very right prefer a movies-only TV channel, while viewers in-between prefer some mix of sports and movies.

Figure 1. Competition in Program Content

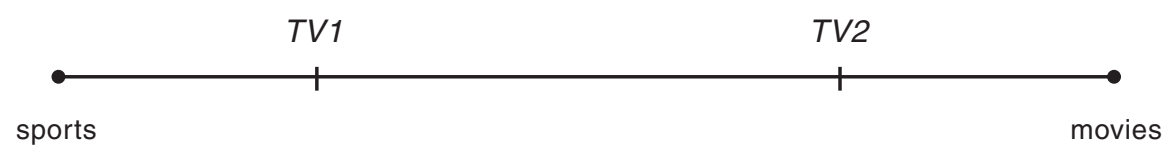

Suppose we have before us a duopoly, as indicated in the figure, with the two TV firms located on the line according to the program mixes they carry: The further to the left in the figure a TV firm is located, the more sports and the less movies there are in the firm's program mix. If the TV firms are both exclusively financed by advertising, then 
the single concern for each of them is to maximize the number of viewers: Advertisers do not care about program content, only about how many viewers a TV channel has, and the more viewers, the more advertisers are willing to pay for an ad on that channel. The implication is that a TV channel financed solely by advertising revenues profits from stealing viewers from its rival channel.

In Figure 1, the more sports oriented TV channel TV1 could increase its viewer clientele by increasing the share of movies in its program mix, thus becoming more similar to $T V 2$ and gaining some of the viewers with preferences currently in-between the two channels without losing any sports addicts at the far left. A similar reasoning leads $T V 2$ to choose a program mix close to that of TV1. The upshot is that the two advertisingfinanced TV channels end up with almost identical program mixes, as depicted in Figure 2. This outcome might be fine for viewers with balanced preferences. However, niche viewers with interests not shared by everyone are not well served. On balance, the verdict in terms of social welfare is that program mixes are too similar. ${ }^{8}$

Figure 2. Advertising-financed TV

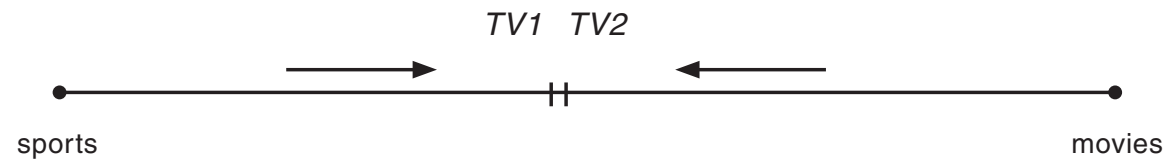

Consider, alternatively, a case of pay TV, where TV firms are financed not only by advertising but also by payments from viewers. Now, viewers care about both the program mix and the price of a TV channel. A TV firm faces a trade-off when determining its program mix. As above, becoming more similar to the rival TV firm steals viewers from the other channel, which in isolation is still a good thing. But now there is a new effect: the more different one TV channel's program mix is from that of the other, the more emphasis a viewer places on the channels' contents, and correspondingly less emphasis will be placed on viewer prices, when choosing which channel to watch. This means that a TV channel that stands out as different from its rival will be able to charge higher prices from its viewers. The trade-off for a TV firm in the pay-TV case is thus that having a content similar to that of its competitors means that the number of viewers is at its highest, which is good for the TV firm's chances on the advertising market, but it also means that the viewer price is at its lowest. In the simple model of Figure 1, the outcome easily becomes the opposite of that of the case of advertising-financed TV, with TV channels now providing pure niche programming, as illustrated in Figure 3. This means that TV channels now have a too differentiated program mix, with too much adherence to the needs of viewers with special interests and too little to that of viewers with balanced interests. ${ }^{9}$

Figure 3. Pay TV

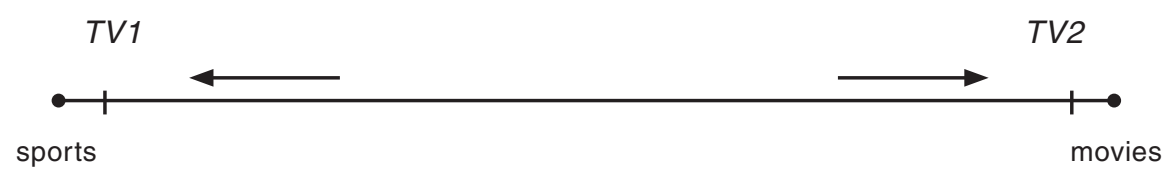


More generally, however, one might think that pay-TV firms choose some kind of middle ground, with program mixes that differ from each other, without being total niche providers. If that is the case, then the implication is that pay TV provides us with a more balanced mix of program content than does advertising-financed TV.

In Scandinavia, public service broadcasting makes a huge presence. In Norway, for example, the state-owned and license-financed Norsk Rikskringkasting (NRK) is without doubt a major player in the television industry and will remain so for the foreseeable future. The question is, of course, whether the presence of a license-financed TV channel would affect the above conclusion that pay-TV leads to more diversity.

Suppose that NRK, as a government institution, ultimately does what is best for society as a whole - that is, that it maximizes social welfare. When advertising-financed, private channels are prone to compete head-to-head, leaving TV viewers with a poor service, as discussed above. The presence of a state-owned channel like NRK, with the interest of society as a whole in mind, would then particularly cater for those specialinterest viewers, alleviating the effect of the private channels' programming. With the introduction of pay TV, private channels do a much better job at serving the whole specter of viewers, and so the role of a state-owned channel is reduced.

An alternative view would be to argue that NRK employees mostly care about their own jobs and therefore seek to get as many viewers as possible in order to maximize the channel's legitimacy among politicians and therefore its chances of keeping its license funding. ${ }^{10}$ This premise would imply that NRK chooses its program content with the aim of maximizing its number of viewers. When its rivals for viewers are purely advertising financed and themselves also merely concerned about their numbers of viewers, the result is a fight for the middle ground, with niche viewers still not being taken properly care of. When the private TV channels move into pay TV, however, and therefore to a greater extent shy away from rival channels' programming, there will be room for a viewer-counting NRK to take care of viewers with balanced interests, inducing the private channels to move even further into niche programming.

In sum, the presence of a state-owned broadcaster does not drastically alter the conclusion from the above discussion: pay TV leads to more diverse programming, whether or not the commercial channels interact with a public one. And as already noted, pay TV also reduces the scope for publicly provided broadcasting to play a role. ${ }^{11}$

\section{Pay TV and Increased Competition}

As discussed above, the introduction of digital terrestrial TV (DTTV) makes room for an increase in the number of firms, since DTTV allows more TV channels to access viewers who only receive over-the-air transmission. In order to analyze the effects of this increased competition on the performance of the TV industry, we need a different take from the one we presented above. Unfortunately, the above analysis is not very suitable for discussing effects of an increase in the number of firms. Also, it may be argued that with many TV channels present, the plurality of program content is no longer a major issue. Let us therefore address the TV industry from another angle: suppose viewers' main concern, when it comes to program content, is variation. ${ }^{12}$ Moreover, let us distinguish between two effects of more TV channels coming into the industry. First we have the mere effect of an increase in the number of firms competing in the market. But there 
is another effect: more TV channels also mean an increase in similarity between TV channels' content as long as new channels, at least in part, aim for mainstream viewers. Interestingly, the effect of increased similarity does not work in the same way as the effect of an increase in the number of firms.

Suppose now that TV firms can receive revenues both from viewers' payments and from advertising. The question is how an increase in competition affects their relative interest in the two sources of revenue. This can tell us something about whether, with increased competition in the TV industry, we can expect pay TV to be on the rise - or the opposite, with advertising being the main source of revenue.

Increased competition can come about in two ways: by an increase in the number of firms in an industry, and by the firms' products becoming more similar and therefore closer substitutes in terms of consumers' preferences. By isolating the two effects in a discussion of the impact of increased competition in the TV industry, we will be able to see how they work in different directions. When a new TV station enters a market, both effects are most likely to be present: there is an increase in the number of firms, and TV stations become more similar because of this new entry. Disentangling the two effects will facilitate a better understanding of the forces behind the final outcome.

As stressed above, the TV industry is a two-sided market with firms addressing both viewers and advertisers. But the two markets behave differently, essentially because viewers dislike the presence of advertisers while advertisers still want to have viewers around. First, take a look at the market for viewers. TV firms' prices to viewers are strategic complements, meaning that, as one firm increases its price, other firms respond by raising their prices, too. Correspondingly, a price decrease at one firm will also lead to price decreases at the other firms in the industry. We might say that viewer prices move in step. This is a regular feature that is found in textbook presentations of price competition. Essentially, a price reduction by one firm decreases the marginal profit from a price increase for each of the other firms, so that their best responses will be to lower prices. ${ }^{13}$

Pricing in the advertising market is different from that in the market for viewers, however, basically because of viewers' dislike of advertising. To see this, suppose that one TV station lowers its price of advertising. This will increase the demand for advertising at that TV station, and therefore increase the quantity of advertising carried. This in turn makes viewers go elsewhere, to TV stations with less advertising. With such an inflow of viewers, these TV stations will observe an increased demand from advertisers, to which they will respond by setting higher prices of advertising. This means that a lower advertising price at one TV firm leads to higher advertising prices at other TV firms. We say that advertising prices are strategic substitutes, or that they move out of step..$^{14}$

Suppose now that the TV channels' program contents become more similar, without there being any change in the number of firms. ${ }^{15}$ This causes the competition for viewers to become fiercer and, in line with viewer prices moving in step, viewer prices to become lower. In the market for advertising, however, quite the opposite happens. Now, advertisers are not particularly concerned about program content. But they do care about the effect of a TV station lowering its viewer price, which creates an inflow of viewers to the TV station. Therefore, since an increase in program-content similarity makes a TV station lower its viewer price and consequently attract more viewers, the demand from advertisers will increase for that TV station. The outcome of all this is that all 
TV stations set lower viewer prices and higher advertising prices as program content becomes more similar. Put differently, advertising's share of TV firms' total revenues is increasing in content similarity.

Suppose next that there is an increase in the number of firms, but no change in content similarity. ${ }^{16}$ As shown by Kind, et al. (2009), an increase in the number of firms simply dilutes a firm's market power in both the viewer market and the advertising market, but more so in the advertising market. Essentially, as long as there is some difference in content among TV stations, a mere increase in the number of firms cannot take away all of a firm's market power in the viewer market. However, this is not true for the advertising market. The outcome is therefore that advertising's share of TV firms' total revenues is decreasing in the number of TV firms competing with each other.

The picture that emerges from this is similar to that of many exercises of economic analysis: What is the effect of increased competition on the prevalence of pay TV? - It all depends. If increased competition first and foremost means more similar content and not so much an increase in the number of firms, then we should expect advertising to be the main source of revenue and pay TV to play a minor role, even with technological developments like DTTV. However, if increased competition means an increase in the number of firms with a minor impact on content similarity, then we can expect pay TV to rise in prominence.

\section{Concluding Remarks}

As my discussion shows, simple answers on the future of pay TV as digitization continues are not easily available. If I may volunteer my opinion, though, I believe that, in the future, we will see an increased role for pay TV as competition increases, implying that, with reference to the previous section, I believe the number effect of increased competition to be greater than the similarity effect. This is what would happen if, for example, most new TV channels entering the industry were niche channels aimed at TV viewers with special program interests. Here, as in so many other circumstances, though, we need to call for the attention of further research in order to be able to predict more carefully in which direction the TV industry will move.

If I am right in my prediction, we can expect the publicly owned broadcasters to play a lesser role in the future. In fact, they may end up looking more and more like their commercial counterparts. Such prospects raise some further questions. One is whether the Norwegian public broadcaster NRK in the future will carry advertising in a manner similar to that of commercial channels. With commercial TV channels relying increasingly on viewer payment for their revenues, we may actually end up with less advertising on TV than what would be socially optimal. In such a case, it would be beneficial for society not only to have advertising on the public broadcaster, but even to have more advertising on the public channel than on the commercial TV channels. ${ }^{17}$

So, in the end, the advent of digital TV may not only cause commercial broadcasters to reconsider their business models, with the likely outcome that more of their revenues in the future will come from viewer payment, and with a smaller role to be played by advertising revenues. With less advertising thus being aired on commercial channels, it may be wise for public broadcasters - and the politicians backing them - to consider the question of whether also they should air advertising in the future. 


\section{Notes}

1. This article is based on a presentation at the $3^{\text {rd }}$ Conference on Cultural Economics entitled "Nouvelles frontières de l'économie de la culture", organized by the Department for studies, strategic foresight and statistics (DEPS) of the French Ministry of Culture and Communication, in Paris, 2-3 October 2008. I am indebted to Hans Jarle Kind and Lars Sørgard for collaboration on several media-economics projects in recent years and for helpful comments on an early draft, and to Åshild Auglænd Johnsen for research assistance. I gratefully acknowledge financial support from the Research Council of Norway's VERDIKT program, through SNF - the Institute for Research in Economics and Business Administration. I am associated with the centre of Equality, Social Organization, and Performance (ESOP) at the Department of Economics at the University of Oslo. ESOP is also supported by the Research Council of Norway.

2. Several pieces of evidence exist corroborating the premise that TV viewers dislike advertising. Wilbur (2008), for example, econometrically estimates a structural model of TV-market competition and finds that viewers' loss from advertising is significant, while Danaher (1995) documents how TV viewers try to avoid advertising breaks. Also on the Internet, advertising seems to be annoying to many content consumers; see, for example, results from a user survey carried out in Norway recently and reported by Bakken (2008). In other media, the picture is more mixed. In particular, many magazines are consumed in part for their advertising; see, for example, Depken and Wilson (2004).

3. For overviews of the literature on two-sided markets, see, for example, Rochet and Tirole (2006) and Evans and Schmalensee (2007).

4. According to the EU Monitoring and Advocacy Program (2005), the four major TV channels' shares of all viewers in European countries are quite high, ranging from $55 \%$ in Germany through $67 \%$ in the UK and $70 \%$ in Italy to $80 \%$ in France. (Numbers are from 2003 or 2004.)

5. See Galperin (2004) and García Leiva, et al. (2006) for discussions of the digital-TV transition in a number of countries.

6. One example is the Norwegian TV channel TV2, which offers premium content based on consumer payments through its Internet service TV2 Sumo, where viewers can subscribe either weekly, monthly, or annually, or simply pay for watching one particular program; see http://webtv.tv2.no/webtv/.

7. One way that TV programs can vary, which is somewhat characteristic for this industry, is by scheduling. See Nilssen and Sørgard (1998) for a discussion of competition between TV channels through the scheduling of their news programs. Another important aspect is program quality. As argued by Motta and Polo (1997), TV channels competing in quality may lead to a state of natural oligopoly, in which an increase in demand does not increase the number of TV channels. Both scheduling competition and quality competition are left out of the present discussion.

8. This argument - that TV channels solely focused on maximizing the number of viewers tend to have too similar content - dates back to Steiner (1952). His analysis was subsequently extended, notably by Beebe (1977). See Owen and Wildman (1992) for a detailed and accessible presentation of the analyses by Steiner and Beebe, and see Gal-Or and Dukes (2003) for a modern treatment of the issue.

9. With consumers uniformly distributed along the line in Figure 1, the social optimum would have each of the two TV channels halfway between the midpoint and one of the extreme positions. I.e., if the possible program mixes belong to the line segment $[0,1]$, with pure sports at 0 and pure movies at 1 , the social optimum locates the two channels at $1 / 4$ and $3 / 4$.

10. There exists anecdotal evidence corroborating this view - such as NRK's actions in the months before the commercial channel TV2's arrival in 1992, when they moved the main news program from 19:30 to 19:00. See Nilssen and Sørgard (1998) for an analysis of this incident.

11. See Armstrong (2005) for a more detailed discussion of the changing role of public service broadcasting as pay TV becomes more prevalent. Although his discussion is more faceted than mine, his conclusion is basically the same: the more commercial TV channels rely on viewer payment, the less scope there is for a publicly owned broadcaster to make a difference.

12. Modelling TV viewers' preferences in terms of variation dates back to Spence and Owen (1977). Their approach was extended, taking into account viewers' disutility from advertising, by Wildman and Owen (1985). However, both these contributions picture the TV industry as one of monopolistic competition, which essentially implies assuming an infinite number of firms in the industry. This makes it impossible to discuss implications of an increase in the number of firms. What is needed is, firstly, a model of a TV oligopoly, and secondly, a specification of viewer preferences that allows us to distinguish between the pure effect of an increase in the number of firms and the effect of increased similarity between them.

Such an analysis is found in Kind, et al. (2007), where viewers' preferences are modeled through a representative viewer endowed with a utility from watching TV given by a version of the so-called Shubik-Levitan utility function, originally formulated by Shubik and Levitan (1980): 
$U=\sum_{i=1}^{m} V_{i}-\frac{1}{2}\left[m(1-s) \sum_{i=1}^{m}\left(V_{i}^{2}\right)+s\left(\sum_{i=1}^{m} V_{i}\right)^{2}\right]$

where $U$ is the representative viewer's utility, $V_{i}$ is the quantity of TV watching consumed by the representative viewer at TV channel $i, m$ is the number of TV channels, and $s$ is a measure of similarity of program content, with $s=1$ implying that program contents are identical, whereas $s=0$ is the opposite extreme with program content being so different that demand for content from various TV channels is independent.

The analysis in Kind, et al. (2007) is based on the presumption that TV firms are totally advertising financed and does therefore not allow for a discussion of pay TV, which is the focus of our present concern. The necessary extension is, however, presented in Kind, et al. (2009), on which the present discussion is based.

A related discussion of viewer vs advertising revenues for the TV industry is found in Godes, et al. (2009), but their set-up does not allow the same disentangling of the effects of an increase in competition as does that of Kind, et al. (2009).

13. See, for example, Vives (1999). The term strategic complements and its twin, strategic substitutes, were coined by Bulow, et al. (1985).

14. This distinction between price competition in the viewer market and price competition in the advertising market is a quite robust result that also shows up in other models of media competition than the one in Kind, et al. (2009) that I focus on here; see, for example, Gabszewicz, et al. (2004).

15. In terms of the utility function in footnote 12 , I analyze the effect of increasing $s$, keeping $m$ fixed.

16. This is a bit of a mind stretcher. But think of all TV stations' program mixes in one big bag, and as a new TV station enters, the bag just becomes bigger without seeming more crowded. In terms of the utility function in footnote 12, I now analyze the effect of increasing $m$, keeping $s$ fixed.

17. The scope for advertising on the public TV channel is discussed further in Kind, et al. (2007).

\section{References}

Armstrong, M. (2005) 'Public Service Broadcasting', Fiscal Studies 26, 281-299.

Bakken, H.R. (2008) 'Reklame før videosnutter på Internett og TV-reklame irriterer mest' (in Norwegian) OMD Norway Nyhetsbrev, 01/31/2008, http://www.imakenews.com/omd/.

Beebe, J.H. (1977) 'Institutional Structure and Program Choices in Television Markets', Quarterly Journal of Economics 91, 15-37.

Bulow, J., J. Geanakoplos, and P. Klemperer (1985) 'Multimarket Oligopoly: Strategic Substitutes and Complements', Journal of Political Economy 93, 488-511.

Danaher, P.J. (1995) 'What Happens to Television Ratings during Commercial Breaks?', Journal of Advertising Research 35, 37-47.

Depken, C.A. and D.P. Wilson (2004) 'Is Advertising a Good or a Bad? Evidence from U.S. Magazine Subscriptions', Journal of Business 77, 61-80.

EU Monitoring and Advocacy Program (2005) 'Television across Europe: Regulation, Policy and Independence', http://www.eumap.org/topics/media/television_europe.

Evans, D.S. and R. Schmalensee (2007) 'The Industrial Organization of Markets with Two-sided Platforms', Competition Policy International 3(1), 150-179.

Gabszewicz, J.J., D. Laussel, and N. Sonnac (2004) 'Programming and Advertising Competition in the Broadcasting Industry', Journal of Economics and Management Strategy 13, 657-669.

Gal-Or, E. and A. Dukes (2003) 'Minimum Differentiation in Commercial Media Markets', Journal of Economics and Management Strategy 12, 291-325.

Galperin, H. (2004) New Television, Old Politics: The Transition to Digital TV in the United States and Britain. Cambridge University Press.

García Leiva, M.T., M. Starks, and D. Tambini (2006) 'Overview of Digital Television Switchover Policy in Europe, the United States and Japan', Info 8(3), 32-46.

Godes, D., E. Ofek, and M. Sarvary (2009) 'Content vs. Advertising: The Impact of Competition on Media Firm Strategy', Marketing Science 28, 20-35.

Hotelling, H. (1929) 'Stability in Competition', Economic Journal 34, 41-57.

Kind, H.J., T. Nilssen, and L. Sørgard (2007) 'Competition for Viewers and Advertisers in a TV Oligopoly', Journal of Media Economics 20, 211-233.

Kind, H.J., T. Nilssen, and L. Sørgard (2009) 'Business Models for Media Firms: Does Competition Matter for How They Raise Revenue?', Marketing Science 28, 1112-1128. 
Motta, M. and M. Polo (1997) 'Concentration and Public Policies in the Broadcasting Industry: The Future of Television', Economic Policy 25, 293-327.

Nilssen, T. and L. Sørgard (1998) 'Time Schedule and Program Choice: TV News in Norway and Denmark', Journal of Economics and Management Strategy 7, 209-235.

Owen, B.M. and S.S. Wildman (1992) Video Economics. Harvard University Press.

Rochet, J.-C. and J. Tirole (2006) 'Two-Sided Markets: A Progress Report', RAND Journal of Economics 37, 645-678.

Shubik, M. and R. Levitan (1980) Market Structure and Behavior. Harvard University Press.

Spence, A.M. and B.M. Owen (1977) 'Television Programming, Monopolistic Competition and Welfare', Quarterly Journal of Economics 91, 103-126.

Steiner, P.O. (1952) 'Program Patterns and Preferences, and the Workability of Competition in Radio Broadcasting', Quarterly Journal of Economics 66, 194-223.

Vives, X. (1999) Oligopoly Pricing: Old Ideas and New Tools. MIT Press.

Wildman, S.S and B.M. Owen (1985) 'Program Competition, Diversity, and Multichannel Bundling in the New Video Industry’, in E.M. Noam (ed.) Video Media Competition: Regulation, Economics, and Technology. Columbia University Press, 244-273.

Wilbur, K.C. (2008) 'A Two-Sided, Empirical Model of Television Advertising and Viewing Markets', Marketing Science 27, 356-378.

TORE NILSSEN, Dr.oecon, Professor of Economics, Department of Economics, University of Oslo, tore.nilssen@econ.uio.no 